\title{
NEW RESULTS ON FINITE-TIME STABILITY FOR NONLINEAR FRACTIONAL ORDER LARGE SCALE SYSTEMS WITH TIME VARYING DELAY AND INTERCONNECTIONS
}

\author{
Pham Ngoc Anh ${ }^{1}$, Nguyen Truong Thanh ${ }^{*}$, Hoang Ngoc Tung ${ }^{2}$ \\ ${ }^{1}$ Hanoi University of Mining and Geology, Vietnam \\ ${ }^{2}$ Thang Long University, Hanoi, Vietnam
}

ABSTRACT

This paper investigates finite-time stability problem of a class of interconnected fractional order large-scale systems with time-varying delays and nonlinear perturbations. Based on a generalized Gronwall inequality, a sufficient condition for finite-time stability of such systems is established in terms of the Mittag-Leffler function. The obtained results are applied to finite-time stability of linear uncertain fractional order large-scale systems with time-varying delays and linear non autonomous fractional order large-scale systems with time-varying delays.

Keywords: Finite-time stability; large-scale systems; fractional order systems; time-varying delays; nonlinear perturbations.

Received: 15/11/2019; Revised: 27/02/2020; Published: 28/02/2020

\section{MộT VÀI KẾT QUẢ MỚI VỀ TÍNH ỔN ĐINH HŨ̉U HẠN CỦA HÊ QUY MÔ LỚN PHI TUYẾN CẨP PHÂN SỐ CÓ TRỄ BIẾN THIÊN VÀ LIÊN KẾT TRONG}

\author{
Phạm Ngọc Anh' ${ }^{1}$, Nguyễn Trường Thanh ${ }^{1 *}$, Hoàng Ngọc Tùng² \\ ${ }^{1}$ Truoòng Đại học Mỏ - Địa chất, Hà Nội, Việt Nam \\ ${ }^{2}$ Truò̀ng Đại học Thăng Long, Hà Nội, Việt Nam
}

\section{TÓM TẮT}

Bài báo này khảo sát tính ổn định hữu hạn của một lớp hệ quy mô lớn cấp phân số có trễ biến thiên và nhiễu phi tuyến. Sử dụng bất đẳng thức Gronwall tổng quát, một điều kiện đủ cho ổn định hữu hạn của các hệ này được thiết lập thông qua hàm Mittag-Leffler. Kết quả thu được sau đó được áp dụng cho hệ bất định và hệ không ôtonom có trễ biến thiên và nhiễu phi tuyến.

Từ khóa: Ổn định hữu hạn; hệ quy mô lớn; hệ phân số; trễ biến thiên; nhiễu phi tuyến.

Ngày nhận bài: 15/11/2019; Ngày hoàn thiện: 27/02/2020; Ngày đăng: 28/02/2020

* Corresponding author. Email: trthanh1999@gmail.com

https://doi.org/10.34238/tnu-jst.2020.02.2341 


\section{Introduction}

Stability analysis of interconnected largescale systems has been the subject of considerable research attention in the literature (see, for example [1], [2]). However, the problem of finite time stability for nonlinear interconnected fractional order large-scale systems with delay still faces many challenges. It is well known that many real-world physical systems are well characterised by fractional order systems, i.e. equations involving non-integer-order derivatives. These new fractional order models are more accurate than integer-order models and provide an excellent instrument for the description of memory and hereditary processes. Since the fractional derivative has the non-local property and weakly singular kernels, the analysis of stability of fractional order systems is more complicated than that of integer-order differential systems. Also, we cannot directly use algebraic tools for fractional order systems since for such a system we do not have a characteristic polynomial, but rather a pseudo-polynomial with a rational power multivalued function. On the other hand, time delay has an important effect on the stability and performance of dynamic systems. The existence of a time delay may cause undesirable system transient response, or generally, even an instability. Moreover, time-varying delays and nonlinear perturbations in systems are inevitable. Very often, an exact value knowledge of the timevarying delay and perturbation is not known or available.

Recently, there have been some advances in stability analysis of fractional differential equations with delay such as Lyapunov stability [3], finite-time stability [4]. Some of them are using Lyapunov function method. In fact, stability problems of nonlinear fractional differential systems have been solved very effectively by the Lyapunov function approach. Some different approaches for the stability of linear fractional order systems, were proposed in [5] via Mittag-Leffler functions, or in [6-7] via a generalized Gronwall inequality. It is worth to note that the using a Gronwall inequality approach does not give satisfactory solution to the stability problem of nonlinear fractional order systems with delay, especially of nonlinear fractional order systems with time-varying delays. The main difficulty in these problems is either in establishing the Lyapunov functional and calculating its fractional derivatives. Note that most of the mentioned papers cope with linear systems without delays and did not consider time-varying delay and nonlinear perturbation. To the best of our knowledge, the finite-time stability problem has not been considered for fractional order systems with delays and perturbations. Motivated by the above discussion, in this paper, we study finite-time stability problem for a class of nonlinear interconnected fractional order large-scale systems subjected to both time-varying delays and nonlinear perturbations. Using a generalized Gronwall inequality, we obtain new sufficient conditions for finite-time stability of such systems. Then the main result is applied to finite-time stability of linear uncertain interconnected fractional order large-scale systems and linear nonautonomous interconnected fractional order large-scale systems with time-varying delay.

The paper is organized as follows. Section 2 presents definitions and some well-known technical propositions needed for the proof of the main results. Mail results and discussion for finite time stability of the system is presented in Section 3. The paper ends with conclusions, acknowledgments, and cited references.

\section{Preliminaries and Problem statement}

The following notations will be used throughout this paper: $R^{+}$denotes the set of 
all real-negative numbers; $R^{n}$ denotes the ndimensional space with the scalar product $(x, y)=x^{T} y$ and the vector norm $|x|=\sqrt{x^{T} x}$; $R^{n \times r}$ denotes the space of all matrices of $(n \times r)$-dimension. $A^{T}$ denotes the transpose of $A$; a matrix A is symmetric if $A=A^{T}$; $\lambda(A)$ denotes all eigenvalues of $A$;

$$
\begin{aligned}
& \lambda_{\text {max }}(A)=\max \{\operatorname{Re} \lambda: \lambda \in \lambda(A)\} ; \\
& \lambda_{\text {min }}(A)=\min \{\operatorname{Re} \lambda: \lambda \in \lambda(A)\} ;
\end{aligned}
$$

$C\left([a, b], R^{n}\right)$ denotes the set of all $R^{n}$-valued continuous functions on $[\mathrm{a}, \mathrm{b}]$; I denotes the identity matrix; The symmetric terms in a matrix are denoted by *.

We first introduce some definitions and auxiliary results of fractional calculus from $[8,9]$.

Definition 2.1. ([8, 9]) The Riemann-Liouville integral of order $\alpha \in(0,1)$ is defined by

$$
I^{\alpha} f(t)=\frac{1}{\Gamma(\alpha)} \int_{0}^{t}(t-s)^{\alpha-1} f(s) d s, t \geq 0 ;
$$

The Riemann - Liouville derivative of order $\alpha \in(0,1)$ is accordingly defined by

$$
D_{R}^{\alpha} f(t)=\frac{d}{d t}\left(I^{\alpha-1} f(t)\right), t \geq 0 ;
$$

The Caputo fractional derivative of order $\alpha \in(0,1)$ is defined by

$$
D^{\alpha} f(t)=D_{R}^{\alpha}[f(t)-f(0)], t \geq 0,
$$

where the gamma function

$$
\Gamma(z)=\int_{0}^{\infty} e^{-t} t^{z-1} d t, \quad z>0 .
$$

The Mittag-Leffler function with two parameters is defined by

$$
E_{\alpha, \beta}(z)=\sum_{k=0}^{\infty} \frac{z^{n}}{\Gamma(\alpha n+\beta)},
$$

where $\alpha>0, \beta>0$. For $\beta=1$, we denote $E_{\alpha}(z)=E_{\alpha, 1}(z)$.
Lemma 2.1. (Generalized Gronwall Inequality [7]) Suppose that $\alpha>0, a(t)$ is a nonnegative function locally integrable on $[0, T), g(t)$ is a nonnegative, nondecreasing continuous function defined on $[0, T), u(t)$ is a nonnegative locally integrable function on $[0, T)$ satisfying the inequality

$$
u(t) \leq a(t)+g(t) \int_{0}^{t}(t-s)^{\alpha-1} u(s) d s, 0 \leq t<T,
$$

then

$u(t) \leq a(t)+\int_{0}^{t}\left[\sum_{n=1}^{\infty} \frac{(g(t) \Gamma(\alpha))^{n}}{\Gamma(n \alpha)}(t-s)^{n \alpha-1} a(s)\right] d s, 0 \leq t<T$.

Moreover, if $a(t)$ is a nondecreasing function on $[0, T)$ then

$$
u(t) \leq a(t) E_{\alpha}\left(g(t) \Gamma(\alpha) t^{\alpha}\right), t \geq 0 .
$$

Consider a class of nonlinear fractional order large-scale systems with time-varying delays composed of $\mathrm{N}$ interconnected subsystems $\sum_{i}, i=\overline{1, N}$, of the form:

$\Sigma_{i}:\left\{\begin{array}{l}D^{\alpha} x_{i}(t)=A_{i} x_{i}(t)+\sum_{j=1}^{N} A_{i j} x_{j}\left(t-h_{i j}(t)\right) \\ \quad+f_{i}\left(x_{i}(t), x_{1}\left(t-h_{i 1}(t)\right), \ldots, x_{N}\left(t-h_{i N}(t)\right)\right), \\ x_{i}(s)=\varphi_{i}(s), s \in[-h, 0],\end{array}\right.$

where

$\alpha \in(0,1) ; x(t)=\left(x_{1}(t), \mathrm{K}, x_{N}(t)\right)^{T}, x_{i}(t) \in R^{n_{i}}$ are the vector states; the initial function $\varphi=\left(\varphi_{1}, \mathrm{~K}, \varphi_{N}\right)^{T}, \varphi_{i} \in C\left([-h, 0], R^{n_{i}}\right) \quad$ with the norm

$$
|\varphi|=\sqrt{\sum_{i=1}^{N}\left|\varphi_{i}\right|^{2}} ;\left|\varphi_{i}\right|=\sup _{s \in[-\mathrm{h}, 0]}\left|\varphi_{i}(s)\right| ;
$$

$A_{i}, A_{i j}$ are known real constant matrices of appropriate dimensions; the delay functions $h_{i j}(t)$ are continuous and satisfy the following condition: $0 \leq h_{i j}(t) \leq h, \forall t \geq 0$;

The nonlinear functions

$$
f_{i}(\cdot):=f_{i}\left(x_{i}, y_{1}, y_{2}, \mathrm{~K}, y_{N}\right)
$$


satisfies the condition

$\exists a>0:\left|f_{i}(\cdot)\right| \leq a\left(\left|x_{i}\right|+\sum_{j=1}^{N}\left|y_{j}\right|\right)$,

for all $x_{i} \in R^{n_{i}}, \quad y_{j} \in R^{n_{j}}, i, j=\overline{1, N}$.

Definition 2.2. For given positive numbers $c_{1}, c_{2}, T$, system (1) is finite-time stable with respect to $\left(c_{1}, c_{2}, T\right)$ if

$$
|\varphi| \leq c_{1} \Rightarrow|x(t)| \leq c_{2}, \quad t \in[0, T] .
$$

\section{Main Results and Discussion}

In this section, we will give sufficient conditions for finite time stability for system (1). Let us first introduce the following notation for briefly:

$$
\gamma=\max _{i}\left|A_{i}\right|+\max _{i} \sum_{j=1}^{N}\left|A_{i j}\right|+(N+1) a .
$$

Theorem 3.1. Given positive numbers $c_{1}, c_{2}, T$, system (1) is finite-time stable with respect to $\left(c_{1}, c_{2}, T\right)$ if

$$
N E_{\alpha}\left(\gamma T^{\alpha}\right) \leq \frac{c_{2}}{c_{1}} .
$$

Proof. Noting that system (1) is equivalent to the following form (see $[4,5])$ :

$$
\left\{\begin{array}{c}
x_{i}(t)=x_{i}(0)+I^{\alpha}\left[A_{i} x_{i}(t)+\sum_{j=1}^{N} A_{i j} x_{j}\left(t-h_{i j}(t)\right)+f_{i}(\cdot)\right], \\
x_{i}(s)=\varphi_{i}(s), s \in[-h, 0] .
\end{array}\right.
$$

Hence, we have for all $t \in[0, T), i=\overline{1, N}$,

$$
\begin{aligned}
\left|x_{i}(t)\right| \leq & \\
\left|x_{i}(0)\right|+ & \frac{1}{\Gamma(\alpha)} \int_{0}^{t}(t-s)^{\alpha-1}\left[\left|A_{i} \| x_{i}(s)\right|\right. \\
& \left.+\sum_{j=1}^{N}\left|A_{i j} \| x_{j}\left(s-h_{i j}(s)\right)\right|+\left|f_{i}(\cdot)\right|\right] d s \\
\leq\left|\varphi_{i}\right|+ & \frac{1}{\Gamma(\alpha)} \int_{0}^{t}(t-s)^{\alpha-1}\left[\left(\left|A_{i}\right|+a\right)\left|x_{i}(s)\right|\right. \\
& \left.+\sum_{j=1}^{N}\left(\left|A_{i j}\right|+a\right)\left|x_{j}\left(s-h_{i j}(s)\right)\right|\right] d s .
\end{aligned}
$$

Consequently,

$$
\begin{aligned}
& \sum_{i=1}^{N}\left|x_{i}(t)\right| \\
& \begin{array}{l}
\leq \sum_{i=1}^{N}\left|\varphi_{i}\right|+\frac{1}{\Gamma(\alpha)} \int_{0}^{t}(t-s)^{\alpha-1}\left[\sum_{i=1}^{N}\left(\left|A_{i}\right|+a\right)\left|x_{i}(s)\right|\right. \\
\left.\quad+\sum_{i=1}^{N} \sum_{j=1}^{N}\left(\left|A_{i j}\right|+a\right) \mid x_{j}\left(s-h_{i j}(s)\right)\right] d s
\end{array} \\
& \leq \sum_{i=1}^{N}\left|\varphi_{i}\right|+\frac{1}{\Gamma(\alpha)} \int_{0}^{t}(t-s)^{\alpha-1}\left[\max _{i}\left(\left|A_{i}\right|+a\right) \sum_{i=1}^{N}\left|x_{i}(s)\right|\right. \\
& \left.\quad+\max _{i}\left(\sum_{j=1}^{N}\left(\left|A_{i j}\right|+a\right)\right) \sum_{i=1}^{N} \mid x_{j}\left(s-h_{i j}(s)\right)\right] d s .
\end{aligned}
$$

Let us set

$$
u(t)=\sup _{\theta \in[-h, t]} \sum_{i=1}^{N}\left|x_{i}(\theta)\right|, t \in[0, T] .
$$

Besides, for all $s \in[0, T]$, we have

$\sum_{i=1}^{N}\left|x_{i}(s)\right| \leq u(t)=\sup _{\theta \in[-h, t]} \sum_{i=1}^{N}\left|x_{i}(\theta)\right|$,

$\sum_{i=1}^{N}\left|x_{i}(s-h(s))\right| \leq u(t)=\sup _{\theta \in[-h, t]} \sum_{i=1}^{N}\left|x_{i}(\theta)\right|$.

Hence,

$\sum_{i=1}^{N}\left|x_{i}(t)\right| \leq \sum_{i=1}^{N}\left|\varphi_{i}\right|+\frac{1}{\Gamma(\alpha)} \int_{0}^{t}(t-s)^{\alpha-1} \gamma u(s) d s$

$=\sum_{i=1}^{N}\left|\varphi_{i}\right|+\frac{1}{\Gamma(\alpha)} \int_{0}^{t} s^{\alpha-1} \gamma u(t-s) d s$.

Note that for all $\theta \in[0, t]$,

$\sum_{i=1}^{N}\left|x_{i}(\theta)\right| \leq \sum_{i=1}^{N}\left|\varphi_{i}\right|+\frac{1}{\Gamma(\alpha)} \int_{0}^{\theta} s^{\alpha-1} \gamma u(\theta-s) d s$,

and the function $u(t)$ is an increasing nonnegative function, we have the function

$$
\int_{0}^{t} s^{\alpha-1} u(t-s) d s
$$

is increasing with respect to $t \geq 0$, and hence, $\sum_{i=1}^{N}\left|x_{i}(\theta)\right| \leq \sum_{i=1}^{N}\left|\varphi_{i}\right|+\frac{1}{\Gamma(\alpha)} \int_{0}^{t} s^{\alpha-1} \gamma u(t-s) d s$.

Therefore, we have

$$
\begin{aligned}
u(t) & =\sup _{\theta \in[-h, t]} \sum_{i=1}^{N}\left|x_{i}(\theta)\right| \\
& \leq \sum_{i=1}^{N}\left|\varphi_{i}\right|+\frac{1}{\Gamma(\alpha)} \int_{0}^{t} s^{\alpha-1} \gamma u(t-s) d s \\
& =\sum_{i=1}^{N}\left|\varphi_{i}\right|+\frac{\gamma}{\Gamma(\alpha)} \int_{0}^{t}(t-s)^{\alpha-1} u(s) d s .
\end{aligned}
$$


Using the generalized Gronwall inequality, Lemma 2.1, we have

$$
\begin{aligned}
u(t) & \leq\left(\sum_{i=1}^{N}\left|\varphi_{i}\right|\right) E_{\alpha}\left(\frac{\gamma}{\Gamma(\alpha)} \Gamma(\alpha) t^{\alpha}\right) \\
& =\left(\sum_{i=1}^{N}\left|\varphi_{i}\right|\right) E_{\alpha}\left(\gamma t^{\alpha}\right) .
\end{aligned}
$$

Moreover, from (2) and the Mittag-Leffler function $E_{\alpha}(\cdot)$ is a nondecreasing function on $[0, T]$, we then have

$$
\begin{aligned}
|x(t)| & \leq \sum_{i=1}^{N}\left|x_{i}(t)\right| \leq u(t) \leq\left(\sum_{i=1}^{N}\left|\varphi_{i}\right|\right) E_{\alpha}\left(\gamma t^{\alpha}\right) \\
& \leq N|\varphi| E_{\alpha}\left(\gamma T^{\alpha}\right) \leq N c_{1} E_{\alpha}\left(\gamma T^{\alpha}\right) \leq c_{2},
\end{aligned}
$$

for all $t \in[0, T]$, which completes the proof of the theorem.

Note that our result can be applied to a uncertain linear fractional order large-scale systems with time-varying delays composed of $\mathrm{N}$ interconnected subsystems of the form

$$
\left\{\begin{aligned}
D^{\alpha} x_{i}(t)= & {\left[A_{i}+\Delta A_{i}\right] x_{i}(t) } \\
& +\sum_{j=1}^{N}\left[A_{i j}+\Delta A_{i j}\right] x_{j}\left(t-h_{i j}(t)\right), \\
x_{i}(s)= & \varphi_{i}(s), s \in[-h, 0],
\end{aligned}\right.
$$

where for all $i, j=\overline{1, N}$,

$$
\Delta A_{i}=E_{i} F_{i}(t) H_{i}, \Delta A_{i j}=E_{i j} F_{i j}(t) H_{i j},
$$

$E_{i}, H_{i}, E_{i j}, H_{i j}$ are given constant matrices, the unknown perturbations $F_{i}(t), F_{i j}(t)$ satisfy for all $t \geq 0$,

$$
F_{i}(t)^{T} F_{i}(t) \leq 1, F_{i j}(t)^{T} F_{i j}(t) \leq 1 .
$$

In this case the perturbations is

$$
f_{i}(\cdot)=\Delta A_{i} x_{i}(t)+\sum_{j=1}^{N} \Delta A_{i j} x_{j}\left(t-h_{i j}(t)\right) .
$$

From the following inequalities

$$
\begin{aligned}
& \Delta A_{i}^{T} \Delta A_{i}=H_{i}^{T} F_{i}(t)^{T} E_{i}^{T} E_{i} F_{i}(t) H_{i} \\
& \leq \lambda_{\max }\left(E_{i}^{T} E_{i}\right) H_{i}^{T} F_{i}(t)^{T} F_{i}(t) H_{i} \\
& \leq \lambda_{\max }\left(E_{i}^{T} E_{i}\right) H_{i}{ }^{T} H_{i} \\
& \leq \lambda_{\max }\left(E_{i}^{T} E_{i}\right) \lambda_{\max }\left(H_{i}^{T} H_{i}\right)=\left|E_{i}\right|^{2}\left|H_{i}\right|^{2} .
\end{aligned}
$$

So

$$
\left|\Delta A_{i}\left\|\leq E_{i}\right\| H_{i}\right| .
$$

Similarly,

$$
\left|\Delta A _ { i j } \left\|\leq\left|E_{i j} \| H_{i j}\right|\right.\right.
$$

For

$$
a=\max _{i, j}\left\{\left|E_{i j}\left\|H_{i j}|,| E_{i}\right\| H_{i}\right|\right\},
$$

we have

$$
\begin{aligned}
\left|f_{i}(\cdot)\right| \leq\left|\Delta A_{i} \| x_{i}(t)\right|+\sum_{j=1}^{N}\left|\Delta A_{i j}\right|\left|x_{j}\left(t-h_{i j}(t)\right)\right| \\
\leq a\left(\left|x_{i}(t)\right|+\sum_{j=1}^{N}\left|x_{j}\left(t-h_{i j}(t)\right)\right|\right) .
\end{aligned}
$$

Then Theorem 3.1 is applied and we have

Corollary 3.1. Given positive numbers $c_{1}, c_{2}, T$, the system (3) is finite-time stable with respect to $\left(c_{1}, c_{2}, T\right)$ if the condition (2) holds.

Furthermore, our result can be applied to the following linear non-autonomous fractional order large-scale systems with time-varying delay

$\Sigma_{i}:\left\{\begin{array}{l}D^{\alpha} x_{i}(t)=A_{i}(t) x_{i}(t)+\sum_{j=1}^{N} A_{i j}(t) x_{j}\left(t-h_{i j}(t)\right) \\ \quad+f_{i}\left(x_{i}(t), x_{1}\left(t-h_{i 1}(t)\right), \ldots, x_{N}\left(t-h_{i N}(t)\right)\right), \\ x_{i}(s)=\varphi_{i}(s), s \in[-h, 0],\end{array}\right.$

where

$\gamma_{0}:=\max _{i}\left(\sup _{t \in[0, T]}\left|A_{i}(t)\right|+\sum_{j} \sup _{t \in[0, T]}\left|A_{i j}(t)\right|\right)<\infty$, the functions $f_{i}(\cdot)$ satisfying the conditions (H1). In this case, using the proof of Theorem 3.1 gives the following result.

Corollary 3.2. Given positive numbers $c_{1}, c_{2}, T$, the system (4) is finite-time stable with respect to $\left(c_{1}, c_{2}, T\right)$ if the condition holds.

$$
N E_{\alpha}\left(\left[\gamma_{0}+(N+1) a\right] T^{\alpha}\right) \leq \frac{c_{2}}{c_{1}} .
$$




\section{Conclusion}

In this paper, we have studied the finite time stability of a class of interconnected fractional order large-scale systems with time-varying delays and nonlinear perturbations. The proposed analytical tools used in the proof are based on the generalized Gronwall inequality. The sufficient conditions for the finite-time stability have been established.

\section{Acknowledgments}

The authors would like to thank the anonymous reviewers for their valuable comments and suggestions which allowed them to improve the paper.

\section{REFERENCES}

[1]. D. P. Siliak, Large-Scale Dynamic Systems: Stability and Structure. North Holland: Amsterdam, 1978

[2]. M. Mahmoud, M. Hassen, and M. Darwish, Large-Scale Control Systems: Theories and Techniques. Marcel-Dekker: New York, 1985.

[3]. S. Liu, X. F. Zhou, X. Li, and W. Jiang, "Asymptotical stability of Riemann-Liouville fractional singular systems with multiple time-varying delays," Appl. Math. Lett., 65, pp. 32-39, 2017.

[4]. R. Rakkiyappan, G. Velmurugan, and J. Cao, "Finite-time stability analysis of fractionalorder complex-valued memristor-based neural networks with time delays," Nonlinear Dynam., 78, pp. 2823-2836, 2014.

[5]. S. Liu, X. Y. Li, W. Jiang, and X. F. Zhou, "Mittag-Leffler stability of nonlinear fractional neutral singular systems," Cотmun. Nonlinear Sci. Numer. Simul., 17, pp. 39613966, 2012.

[6]. M. P. Lazarevic, and D. Lj. Debeljkovic, "Finite-time stability analysis of linear autonomous fractional-order systems with delayed state," Asian J. Control, 7, pp. 440447, 2005.

[7]. H. Ye, J. Gao, and Y. Ding, "A generalized Gronwall inequality and its application to a fractional differential equation," J. Math. Anal. App., 328, pp. 1075-1081, 2007.

[8]. A. A. Kilbas, H. Srivastava and J. Trujillo, Theory and Applications of Fractional Differential Equations. Amsterdam: Elsvier, 2006.

[9]. I. Podlubny, Fractional Differential Equations. Academic Press, San Diego, 1999. 